\title{
El Plan Turístico de Ciudades Medias: el interior avanza
}

Antonio Muñoz Martínez. Director General de Planificación y Ordenación Turística. Consejería de Turismo, Comercio y Deporte, Junta de Andalucía

\section{La Red de Ciudades}

\section{Medias pretende}

conformar un espacio

común que supone una

gestión turística del

producto-territorio

\section{generado}

El Sistema Turístico Andaluz y el papel de las ciudades medias del interior de Andalucía

Las ciudades medias de interior se pueden considerar como parte del patrimonio territorial de Andalucía, puesto que no existe en ninguna otra región de España ni de Europa un sistema urbano con un peso tan importante de este tipo de ciudades. Esta situación hace que las ciudades medias del interior adquieran un papel clave para la estructuración y vertebración del territorio andaluz desde el plano social y económico. Este tipo de ciudades, por razones históricas y funcionales, ha jugado, y juega hoy, un papel clave en la articulación territorial de Andalucía, lo que ha posibilitado que tengan un patrimonio de extraordinaria importancia y estén dotadas de un especial dinamismo social y económico, de manera que están llamadas a convertirse en uno de los ejes estratégicos para el futuro de esta comunidad.

En el marco de este nuevo dinamismo, la mayoría de estas ciudades ha emprendido en los últimos años una estrategia clara de fomento de la actividad turística, lo que les está llevando a poner en valor algunos de los recursos patrimoniales con potencialidad turística y a que surjan iniciativas empresariales que dan cobertura a los servicios turísticos. En este orden de cosas, el Sistema Turístico Andaluz se empieza a caracterizar por una necesaria complementariedad entre la oferta de sol y playa y el turismo de interior. Y es precisamente aquí donde las ciudades medias de interior pueden aportar un impulso significativo a esa complementariedad por su importancia histórica y funcional. Esta nueva tendencia, además, viene a confirmar los cambios que se están produciendo en la demanda turística, en torno a los cuales es necesario dar respuesta a los gustos y expectativas de nuevos turistas que quieren visitar el interior de Andalucía en busca de lo auténtico, y donde la oferta patrimonial del interior se convierte en una pieza clave.

Pero también es cierto, que en el estado actual de desarrollo turístico de estas ciudades medias del interior de Andalucía existen importantes retos que abordar, para que realmente éstas puedan jugar el papel que les va a tocar. De esta manera, el reto más importante al que tienen que enfrentarse es el de conseguir un tamaño crítico que les permita convertirse en un producto turístico de base territorial, en un microdestino en Andalucía, pues- 
- Fachada del Museo Palacio Abacial, Alcalá la Real (Jaén) / JuAn CARlos CAZALLA, IAPH

to que muchas de estas ciudades, por los recursos realmente visitables y por la dimensión de los servicios turísticos que tienen, no podrán articularse como producto turístico territorial. Se hace necesario, por tanto, que las ciudades medias del interior trabajen en red, para que a través de la cooperación, y en base a una realidad territorial compartida, puedan conseguir la dimensión necesaria de destino, o producto turístico.

\section{El Plan Turístico de las Ciudades Medias del Centro de Andalucía: un ejemplo de trabajo en red}

En este marco, nace la Red para el Desarrollo Turístico de las Ciudades Medias del Centro de Andalucía, que es una asociación de ciudades que integra a los ayuntamientos de Alcalá la Real (Jaén), Antequera (Málaga), Écija, Estepa (Sevilla), Loja (Granada) y Lucena (Córdoba) y que tiene como finalidad el impulso de la cooperación en materia de turismo con el objetivo fundamental de articular un producto turístico en la zona centro del interior de Andalucía.

El objeto básico de esta red de ciudades consiste en la creación de un producto turístico entre las mencionadas seis ciudades

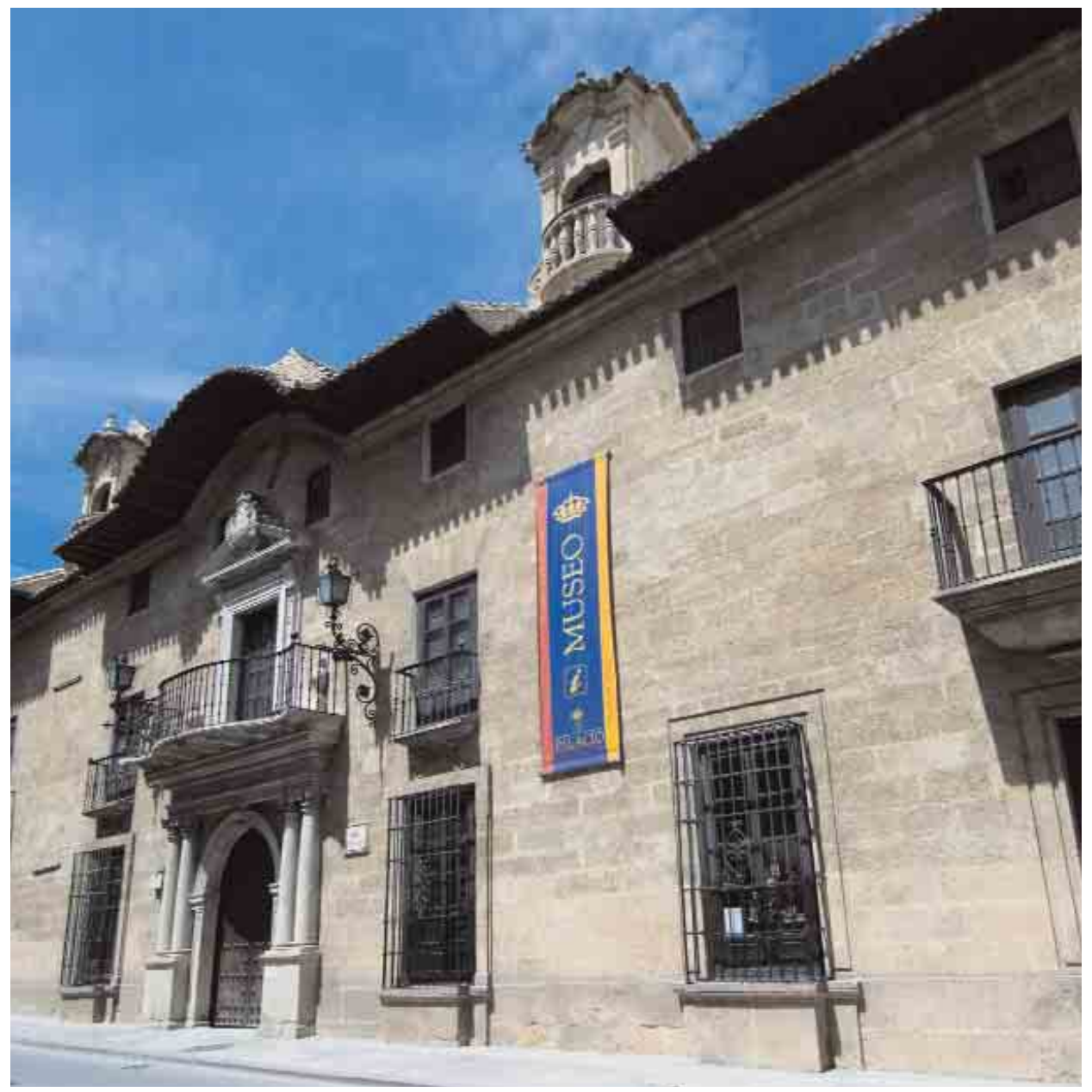


que va más allá de un itinerario o ruta turística. Se pretende conformar un espacio turístico común que será el soporte de una oferta integral constituida por los recursos patrimoniales más importantes de las ciudades y la oferta de servicios turísticos de calidad que implicará una gestión turística común e integrada del producto-territorio generado. Supone, por tanto, un avance significativo con respecto a otros proyectos que se articulan como itinerarios entre ciudades o simples medidas de colaboración entre ellas. La Red de Ciudades Medias implica una gestión propia e individualizada de este producto, a la vez coordinada con la acción turística que cada ciudad de la red impulse a nivel local.

Consciente de este proyecto y del extraordinario esfuerzo emprendido por estas seis ciudades, el 21 de diciembre de 2005 se firmó un convenio de colaboración entre la Consejería de Turismo, Comercio y Deporte de la Junta de Andalucía y la Red para el Desarrollo Turístico de las Ciudades Medias del Centro de Andalucía para la ejecución de un Plan Turístico que será el instrumento básico de articulación del proyecto de cooperación turística entre las ciudades integrantes de la red por la cantidad de $19045000 €$ que serán financiados conjuntamente por la Consejería y los ayuntamientos que componen la red. El Plan Turístico de Ciudades Medias será la herramienta a través de la cual se podrá conseguir el objetivo perseguido por la red de generar un producto turístico integral que tendrá como base la oferta patrimonial de las ciudades implicadas.

Este proyecto se articula en torno a cinco grandes líneas estratégicas:

Dotación de una estructura de gestión La generación de un producto turístico común e integral implica la necesidad de establecer una estructura de gestión propia e individualizada como una institución diferenciada de los ayuntamientos que constituyen la red, aunque plenamente coordinada con ellos, puesto que no se trata de una colaboración puntual entre ciudades, sino de una verdadera cooperación que implica el desarrollo de actuaciones conjuntas. Esta estructura de gestión será la encargada de:

$\rightarrow$ Impulsar las actuaciones y proyectos contenidos en el Plan Turístico de Ciudades Medias. $\rightarrow$ Gestionar los recursos patrimoniales de cada una de las ciudades de la Red que se integren en el producto turístico integral.

$\rightarrow$ Promocionar el producto turístico.

$\rightarrow$ Realizar acciones de comercialización turística.

$\rightarrow$ Determinar los criterios de calidad de la oferta de servicios turístico y controlar la integración de las iniciativas privadas dentro de la red.

\section{Configuración del producto turístico territorial}

La base de la oferta del producto turístico de las ciudades medias estará constituida por el establecimiento de un espacio turístico tematizado dentro de cada una de las seis ciudades. Para la configuración de dicho espacio turístico se desarrollarán las siguientes medidas:

$\rightarrow$ La Creación de un Centro de Interpretación de la ciudad que servirá como centro de recepción de visitantes que permitirá la interpretación del valor de la ciudad en la historia de Andalucía y de sus recursos patrimoniales y servirá como punto de inicio de la visita a los recursos patrimoniales integrados en la oferta de la ciudad.

$\rightarrow$ Delimitación de un espacio turístico dentro de cada una de las ciudades articulado a través de un eje temático que incluya una zona turística diferenciada en la que se sitúan los recursos turísticos visitables. Para la delimitación de dicho espacio turístico se utilizará un itinerario temático señalizado y la aplicación de las nuevas tecnologías que permitan al turista guiar el recorrido por dicho espacio turístico, la identificación de los recursos patrimoniales visitables y su interpretación.

$\rightarrow$ Gestión por parte de la Red de los recursos patrimoniales incluidos en el espacio turístico 


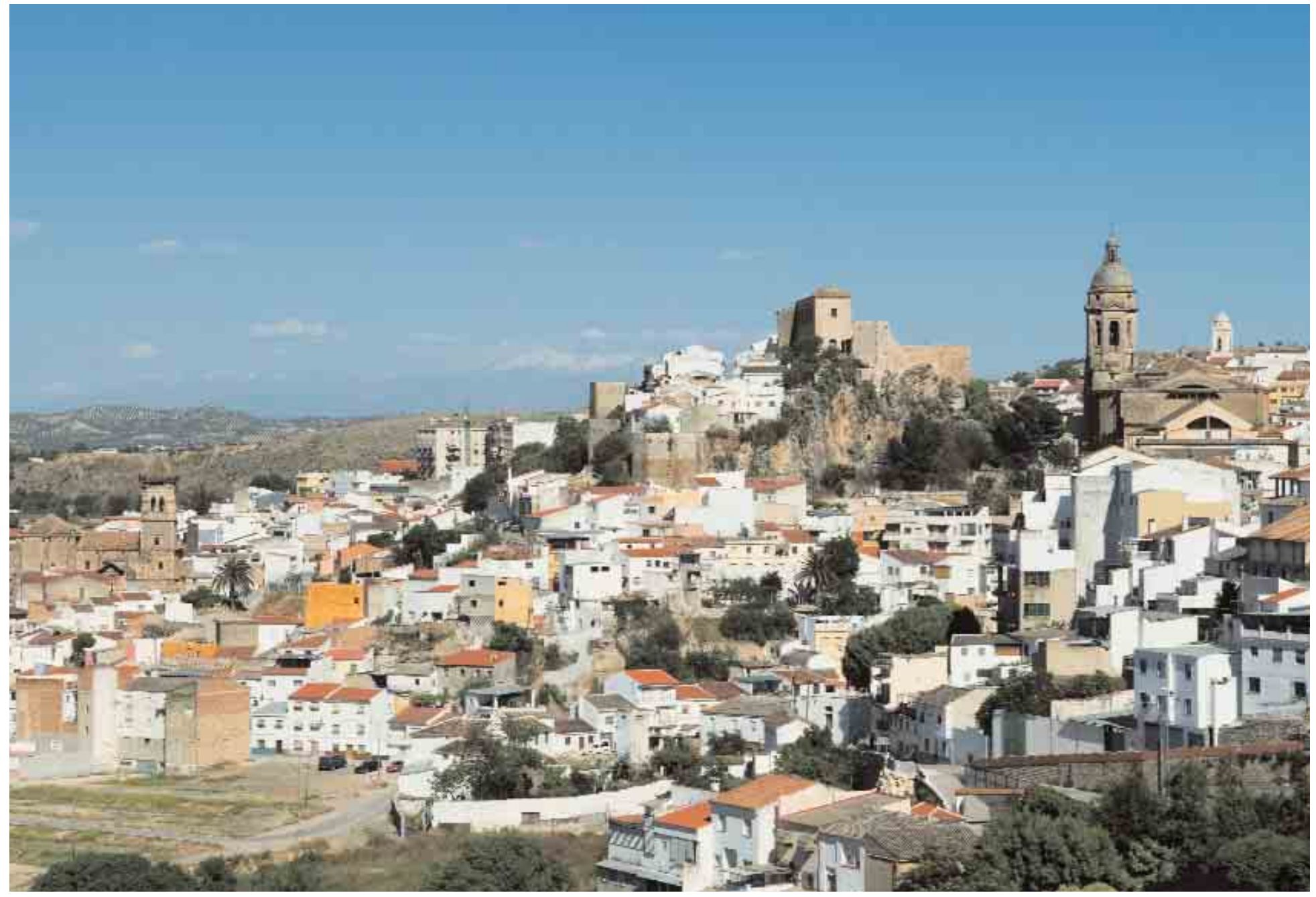

Alcalá la Real,

Antequera, Écija,

Estepa, Loja y Lucena

son las seis ciudades

andaluzas que integran

la red 


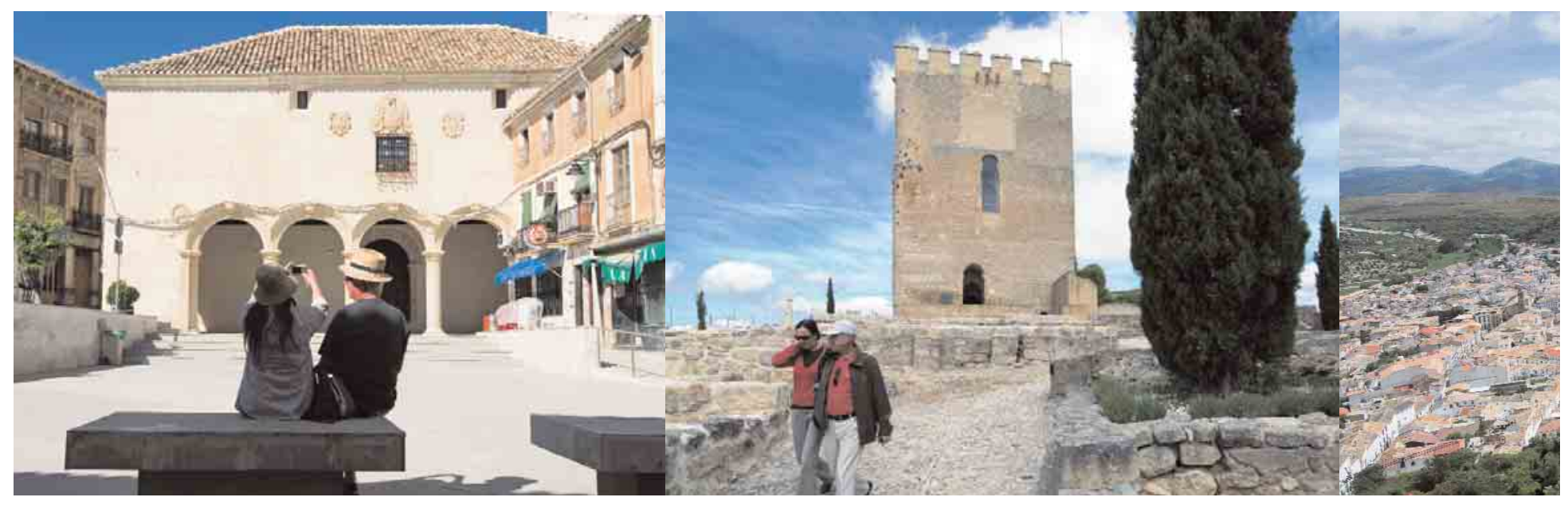

(1) Plaza de Joaquín Costa, Loja (Granada) / JuAn CARLos CAZALLA, IAPH

(1) Ciudadela de la Mota (Alcalá la Real, Jaén) / JuAn CARLos CAZALLA, IAPH

de la ciudad que implicará la apertura al público y gestión de las visitas a dicho recurso, y el establecimiento de un sistema integrado de entradas.

$\rightarrow$ Mejora estética de los entornos de los recursos turísticos incluidos en el eje temático de cada una de las ciudades.

Promoción turística

Será necesario realizar acciones de promoción turística del producto turístico generado

Comercialización turística

Para complementar el proceso productivo del producto turístico integral se realizarán acciones de intermediación turística con el objetivo de comercializar y situar en los mercados el producto de ciudades medias que conforma esta red de ciudades.

Integración de la iniciativa privada

La implicación de la iniciativa privada en el proyecto se convierte en una de las líneas estratégicas fundamentales, y se articulará a través de dos medidas:

$\rightarrow$ La implicación de las asociaciones de empresarios en la configuración de los criterios de gestión del proyecto.

$\rightarrow$ El establecimiento de un programa de calidad que permita fijar los criterios y los mecanismos de incorporación de los servicios turísticos de las ciudades en la oferta integral de la red.

\section{Hacia una nueva estrategia para potenciar} el turismo en las ciudades medias del interior de Andalucía

La Consejería de Turismo, Comercio y Deporte de la Junta de Andalucía es consciente del nuevo papel que van a jugar las ciudades medias del interior de Andalucía y sobre la base del proyecto antes mencionado y lo que viene estableciéndose en el Plan General de Turismo Sostenible de Andalucía, la Dirección General de Planificación y Ordenación Turística ha puesto en marcha la Iniciativa de Ciudades Turísticas dentro de la Estrategia de Turismo Sostenible que pretende el impulso de nuevas redes de ciudades medias del interior de Andalucía que se puedan convertir, en base a la coherencia territorial, en productos turísticos articulados estratégicamente. En definitiva, se trata de aprovechar al máximo la potencialidad turística de las ciudades medias patrimoniales del interior de nuestra región y de dotar a estas ciudades de un papel clave en hacer nuestra oferta más auténtica y diversa. 